\title{
CLUBE DE CINEMA FERRIS: A LINGUAGEM CINEMATOGRÁFICA NO ÂMBITO ESCOLAR
}

\author{
JOÃO PESSOA/PB JULHO/2018
}

\author{
William Bezerra Da Silva - UFPB/DEMID - williamresista@gmail.com \\ Signe Dayse Castro De Melo E Silva - UFPB/DEMID - signedayse@yahoo.com.br \\ Hercilio de Medeiros Sousa - UFPB/DEMID - contato@herciliomedeiros.com.br \\ Késsia Lopes Dutra - UFPB/DEMID - dutraissek@gmail.com \\ Keyla Regina Oliveira Bonifacio - UFPB/DEMID - keylajob@gmail.com
}

Tipo: Relato de Experiência Inovadora (EI)

Categoria: Métodos e Tecnologias

Setor Educacional: EDUCAÇÃO INFANTIL E FUNDAMENTAL

\begin{abstract}
RESUMO
O projeto clube de cinema Ferris foi fundado em 2017 em uma escola pública do Estado da Paraíba e tem como esfera educativa promover e ingressar os alunos do ensino fundamental no estudo da linguagem cinematográfica, agregando valores culturais e artísticos que possam influenciar no processo de ensino-aprendizagem levando em consideração a interdisciplinaridade através da criação de argumentos e roteiros feitos pelos estudantes, para que desta forma os discentes tenham mais contato com a escrita da língua portuguesa. O uso de grupo fechado em página do facebook foi um facilitador nos estudos a distância (EAD) como ferramenta extraescolar, levando com facilidade os envios de arquivos, textos e vídeos que embasaram os estudos teóricos sobre o cinema e o processo de argumento e roteiro como ferramenta pedagógica, por sua vez, o canal do Youtube foi usado como plataforma das exibições dos vídeos dos alunos e também como instrumento de incentivo para os futuros participantes deste projeto, para que desta maneira os alunos possam fazer da escola, a estrutura e a base para um ensino divertido e de qualidade, levando em consideração o protagonismo e a formação intelectual dos estudantes pelo viés do audiovisual.
\end{abstract}

Palavras-chave: Cinema. Roteiro. Argumento. Projeto. Escola. 


\section{Introdução}

É notório que o ensino público brasileiro passa por problemas graves que vão desde questões sociais, evasão escolar e falta de infraestrutura que acarretam no "empobrecimento da instituição escolar", todavia a partir da observância do comportamento dos alunos devido ao uso dos celulares na escola Estadual Maria Honorina Santiago foi realizado um trabalho de intervenção audiovisual nesta escola, para que desta forma eles pudessem produzir de maneira educativa e mais profissional vídeos que agregassem valores culturais as suas vidas.

O projeto tem base teórica na experiência de escolas públicas da capital Recife, que estão relatadas no livro: Projeto Didático para a construção de documentário: uma possibilidade de experiência populares em escolas públicas, da autoria de Rui G. M. Mesquita. Este livro aborda documentários como expressões reais a serem mostradas aos alunos como ferramenta pedagógica a partir da produção documental, como produção e pós produção e além de conhecer a comunidade em que os alunos estão inseridos, tudo isso através de documentários.

\footnotetext{
Uma diferença entre os documentários e os filmes de ficção, que ao mesmo tempo ajuda a entender o que são mesmo os documentários, está relacionado aos sujeitos que são filmados e a suas formas de se expressar [...] Assim, como os diálogos não podem ser previamente escritos e costumam não ser totalmente previsíveis, diz-se que um documentário é o "argumento-encontrado". (MESQUITA, 2013, p. 39)
}

Apesar de extremamente importante a argumentação deste projeto de documentários em escolas públicas, e sendo uma fonte inspiradora para outros projetos assim como foi para o clube de cinema Ferris, este tem um viés mais voltado para o estudo da roteirização da escrita dos próprios alunos, e também um estudo relacionado as ferramentas midiáticas, como uso do youtube, debate sobre o discurso dos youtubers, surgimento do cinema e gêneros textuais tudo para que o projeto trabalhe com toda esfera que norteiam o audiovisual e suas linguagens, ou seja, ensinar aos alunos do fundamental a ter uma visão mais crítica e impulsiona-los na produção textual usando ferramentas simples como o uso de celular para criação de microcurtas no âmbito escolar.

Nesta perspectiva;

Tais normas de formação das imagens podem ser assimiladas pelos alunos como conhecimento e aplicação prática recriadora e atualizada em seus trabalhos, conforme seus projetos demandem e sua sensibilidade e condições de concretizá-los permitam. O aluno também cria suas poéticas onde gera códigos pessoais. (PCNs, 1997, p.40).

A experiência deste projeto é dar voz e criar uma identidade própria dos alunos através das expressões audiovisuais, é dar sentido a escola a forma como ela deve tratar o 
aluno, ressaltando um ambiente de criatividade que gere seus próprios "códigos pessoais".

\section{A produção de conteúdos}

Em consonância com o artigo 4ํำ da LDB (Leis de Diretrizes e Bases da Educação). "O ensino fundamental será presencial, sendo o ensino a distância utilizado como complementação da aprendizagem ou em situações emergenciais".

A LDB é o guia e uma ferramenta norteadora para designar as leis que regem a educação no país, no trecho citado é notório que o ensino a distância tem a sua importância no ensino fundamental para complementação curricular, é desta maneira que os meios midiáticos, a exemplo das redes sociais, Youtube e entre outros entram como forma extraescolar para o processo de ensino-aprendizagem.

Pensando nisso, criação de páginas do facebook tem um valor significativo para o processo de aprendizagem dos alunos, uma vez que o método de envio de arquivos no facebook tem uma facilidade maior e também gera a interação entre os grupos de estudos, neste caso o projeto Clube de cinema Ferris, onde pela página de um grupo fechado foi possível o envio dos materiais para os estudantes participantes do Clube de cinema Ferris estudarem sobre a origem do cinema, técnicas cinematográficas, criação de roteiros, envios de fotografias e textos motivadores.

Nesta fase do ensino fundamental muitos estudantes têm uma curiosidade mais aguçada, portanto qualquer novidade ou algo que seja postado em páginas do facebook, ou vídeo em canal do Youtube vai chamar atenção deste público sem a necessidade de uma possível explicação de um professor em sala de aula. Kenski (2010) diz que a educação a distância deve envolver todos os recursos tecnológicos, seja também pelo impresso ou digital que envolva a capacidade de escolha do aluno, seja pela presencial ou a distância, trazendo ao aluno novidades e um processo de democratização dos estudos através das diversas vertentes da tecnologia.

\section{Nossos conceitos fundamentais}

O clube de cinema Ferris surge a partir de uma observação onde os alunos até então tinham a dança, o teatro e a pintura como artes conhecidas no âmbito escolar, todavia a lacuna entre $o$ ato de fazer audiovisual na escola estava em aberto, embora alguns alunos já faziam de forma indireta a criação de vídeos, contudo sem a roteirização. $O$ embasamento teórico do livro: Projeto didático para a construção de documentários: uma possibilidade de experiência popular em escolas públicas (2013), proporcionou um despertar em nosso projeto.

Uma das bases do livro está na troca de experiência entre os docentes e o ato de fazer 
audiovisual na escola pública, especificamente documentários;

Assim, a obra propõe uma discussão muito cuidadosa sobre como as práticas escolares com a utilização e documentário podem entrar no debate acerca do processo cultural, servindo como uma ferramenta pedagógica problematizadora dos sentidos uniformizadores, estáticos, individualistas que se materializam no currículo escolar. (LIMA, 2013, p. 13)

Há vários estudos sobre cinema e educação, mas cada um com suas singularidades e contextos sociais diferentes, enquanto uns trabalham apenas documentários e usam questões éticas, sociais, racismo e gêneros em seus estudos, outros usam a produção de vídeo voltados mais a educação ou vídeos institucionais.

Nosso projeto tem uma maior abrangência por se tratar da interdisciplinaridade uma vez que a produção textual de histórias ficcionais, como a criação de diálogos, ou seja, o constante uso da língua portuguesa e o estudo das artes como composição da linguagem cinematográfica se adentra como aspecto interdisciplinar.

Segundo os Parâmetros Curriculares Nacionais:

Essa articulação interdisciplinar intra-área não deveria ser vista simplesmente como um produto novo, a ser apresentado à escola pois, sob certos aspectos, é uma dívida antiga que se tem [...] Uma parcela dessa dívida poderia ser paga com a apresentação de uma linguagem e da nomenclatura realmente comuns entre várias das disciplinas. (PCNs, 1997, p. 20)

Assim, ao abrir espaço para outras disciplinas temos métodos que agregam valores de aprendizagem não apenas focalizada em um estudo audiovisual, mas sim toda esfera que norteiam a escola, inclusive o estudo da língua portuguesa tão abordada nos PCNs. A disciplina de língua portuguesa é também considerada a qual os alunos têm mais dificuldades, inclusive na análise e interpretação textual.

Um ensino fundamental bem realizado é uma porta de entrada para as próximas etapas de ensino, a criança ou o adolescente que tem uma base educacional estruturada no ensino fundamental, tem a chance de chegar ao ensino médio com uma visão bem mais ampla sobre o universo em que eles estão inseridos.

O incentivo na criação de argumentos e roteiros criados pelos próprios alunos e divulgados na página do facebook do clube de cinema Ferris podem incentivar o gosto pela leitura e a escrita. Amaral et al (2012, p.4) afirma: "Também é preciso que os problemas relacionados ao ensino de língua portuguesa sejam solucionados, como por exemplo, a falta de leitura [...]". Neste viés a amplitude do audiovisual se estende além de edições de vídeo, interpretações de atores, trilha sonora, direção, técnicas cinematográficas e vai ao encontro de outras esferas da área da educação.

Através da elaboração deste mapa conceitual, podemos observar uma estruturação ou ramificação a partir da ótica audiovisual, ou seja, por ela podemos adentrar em outras 
vertentes do ensino aprendizagem.

\section{4 - Resultados e projeções}

O Clube de Cinema Ferris foi realizado pelo professor de língua inglesa William Bezerra e alunos da E. E. F. M Maria Honorina Santiago, situado na cidade de Santa Rita, Paraíba. O projeto teve início em agosto e término em novembro de 2017, o objetivo do projeto é ingressar os alunos do ensino fundamental no universo da sétima arte. Foram escolhidos 25 alunos para esse projeto piloto e estes teriam a incumbência de promover o audiovisual na escola.

Os 25 estudantes foram escolhidos de acordo com suas habilidades, bem como; desenhos, edição de vídeo por celular, escrever histórias, gostar de moda, fotografias, filmagens e entre outros, a escolha destes é pelo fato de poder dar mais atenção a todos os participantes deste projeto uma vez que agregar turmas inteiras com mais de 300 crianças e adolescentes com apenas um coordenador ficaria inviável para correção de trabalhos, como; roteiros, argumentos, microfilmes e figurinos, o que poderia acarretar na má qualidade do projeto, todavia, estes 25 serão multiplicadores da linguagem cinematográfica no âmbito escolar, incentivando os outros discentes da escola Estadual Maria Honorina Santiago a participarem dos próximos eventos de cinema na escola. No mês de novembro houve uma exibição em toda a escola das produções feitas pelos próprios alunos. Seguimos também as ideias iniciais e esquematizadas no fluxograma abaixo:

Imagem 1 - Fluxograma 


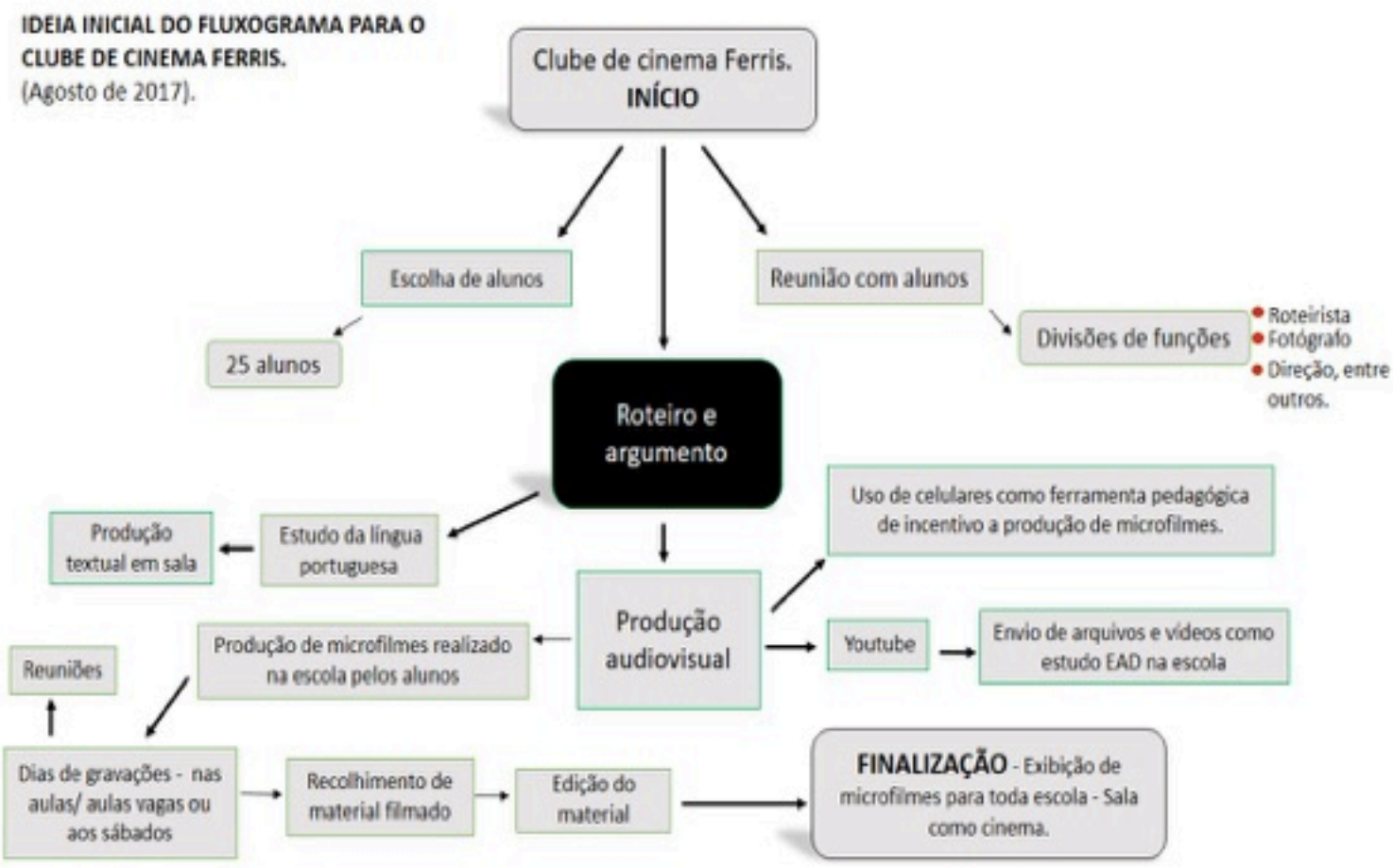

Fonte: produzido pelo autor (2018)

Acrescentando o material pedagógico do clube de cinema Ferris tivemos também o conteúdo programático:

\section{. Breve histórico do cinema}

. Criação de argumento e roteiro

. Estudo das câmeras

. Noção de ângulos

. Uso do figurino

. Técnica de atuação

. Uso de editor de vídeos

Trechos de filmes que mostram valores éticos, o amor pela família, divisões de classes e entre outros, sendo que neste contexto os trechos dos filmes são usados como processo reflexivo uma vez que filmes e séries exercem uma influência grande neste público, ao ponto de mudar o comportamento deles, seja no modo de vestir, de falar e até mesmo em uma futura escolha de profissão.

Durante três meses alguns alunos do ensino fundamental, principalmente os estudantes do $8^{\circ}$ e $9^{\circ}$ ano se reuniram para criar pequenos microfilmes para um aprendizado sobre a linguagem cinematográfica, como roteiro, fotografia, história do cinema, planos cinematográficos e entre outros.

Em nosso primeiro encontro realizado em agosto de 2017, nos reunimos para o teste de 
elenco (os alunos), foi mostrado aos participantes como funcionaria o projeto e as responsabilidades que cada um exerceria no Clube de Cinema Ferris.

Foram delegadas a função de diretor ao aluno Allan da Fonseca, o qual também editava os vídeos e trabalhava com a fotografia dos microfilmes. Roteiro para Izabel Alves e Danilo, figurino de Maria Vitória.

Atores; Gabriel Moreira, Guilherme, Rai, Lorena, Wellington Viegas, Mirelly Santos, Letícia e Clemilson. Todos estes tiveram participação efetiva no projeto.

Imagem 2 - Gravações: "Fica comigo". Aluna do 8ํano.

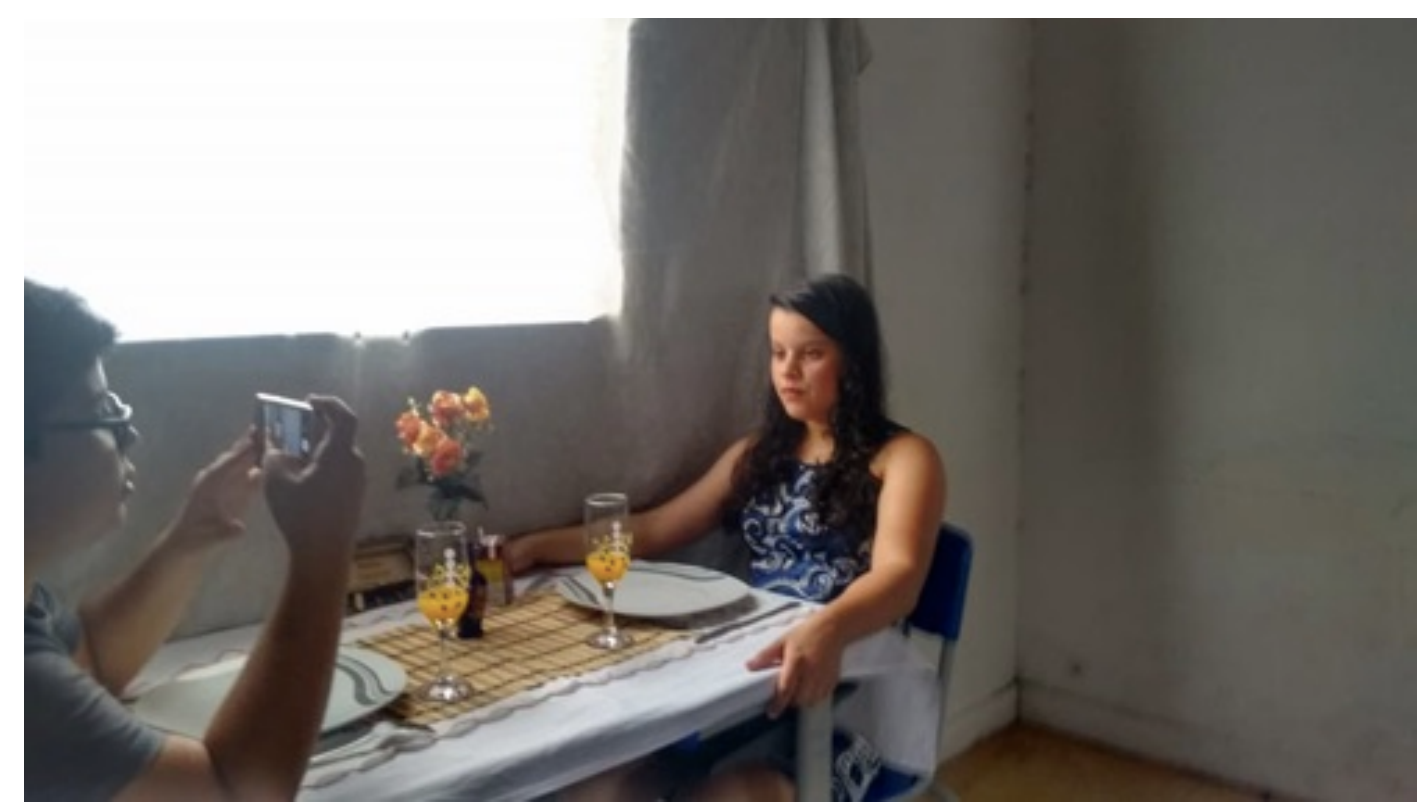

Fonte: Do autor (2018)

Imagem 3 - Gravações:" A morte na rua". Alunos Guilherme e Mirelly. 


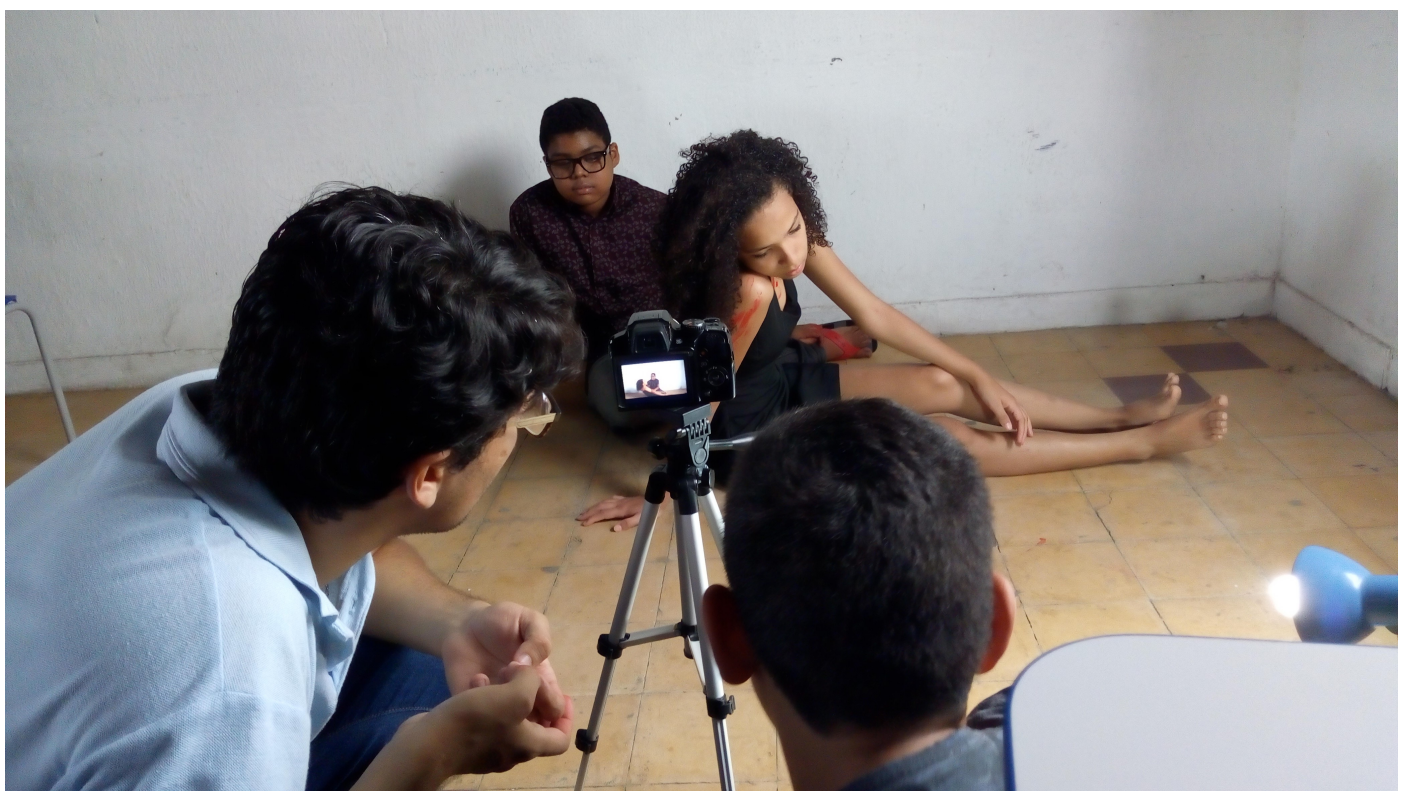

Fonte: Do autor (2018)

Segundo encontro foi a gravação da cena de SER OU NÃO SER inspirado em Hamlet de William Shakespeare. Nesta cena fomos tomado pelos desafios de iluminação já que precisávamos de uma ambientação mais escura. As demais cenas foram realizadas durante alguns sábados, entre elas o clipe realizado pelos alunos Wellington Viegas (9ํㅜㅇ ano) e Mirelly Santos ( $8^{\circ}$ ano).

O clipe é em homenagem a Elvis Presley. Outra cena foi A MORTE NA RUA realizado por Guilherme ( $8^{\circ}$ ano) e Mirelly ( $8^{\circ}$ ano), esta cena fala sobre um jovem que por causa da violência que assola a humanidade acaba perdendo de uma forma violenta a sua amiga. E por fim a cena de Clemilson, aluno do $8^{\circ}$ ano o qual fez uma reportagem no estilo $\mathrm{G} 1^{1}$.

O projeto ainda continua sendo exibido na escola e tem um canal no youtube ${ }^{2}$ com todos os vídeos, inclusive bastidores de todo o processo de gravação. Muitos alunos que viram o projeto pronto com todos os vídeos editados tiveram interesse em continuar no clube de cinema Ferris.

Os participantes (estudantes) mais efetivos; Lorena, Wellington Viegas, Mirelly, Guilheme, Maria Vitória, Allan da Fonseca, Isabel Alves e Clemilson desejam dar continuidade ao clube de cinema Ferris, com isso entende-se que o projeto foi um grande incentivador para muitos alunos da escola Maria Honorina Santiago, principalmente os envolvidos no Clube de Cinema Ferris, estes participantes foram multiplicadores e incentivadores de cultura do audiovisual na escola pública Maria Honorina Santiago. Neste ano de 2018 temos a incumbência de criar um documentário relacionado ao patrimônio escolar, em paralelo com criações de argumento e roteiros ficcionais.

Hoje o clube de cinema Ferris é um grande motivador para a escola e tem levado alunos 
de outras turmas e turnos a compreender que esta instituição vai além dos livros, dos cadernos, do ato de copiar do quadro e de algumas regras da escola. $O$ audiovisual está a favor de uma leitura de mundo, onde os estudantes são protagonistas de um ambiente que enxerga o aluno como um agente transformador do meio em que eles estão inseridos.

\section{Referência}

AMARAL, et al. Desafios da língua portuguesa no ensino fundamental. Revista cientifica eletrônica de pedagogia, 2013. Disponível em: . Acesso em: 27 Abr. 2018.

BRASIL. Parâmetros curriculares nacionais (PCN's): arte. Ensino fundamental. Brasília: MEC/SEF, 1997.

BRASIL. Ldb. Lei ํo 9.394, de 20 de dezembro de 1996. Estabelece as diretrizes e bases da educação nacional, Brasília, DF, 1996.

MESQUITA, Rui. Projeto Didático para a construção de documentários: uma possibilidade de experiência popular em escolas públicas. Recife: Ed. Universitária da UFPE, 2013.

KENSKI, V. M. O desafio da educação a distância no Brasil. Revista edufoco, 2010. Disponível em: < http://www.ufjf.br/revistaedufoco/files/2010/02/011.pdf >. Acesso em: 22 Abr. 2018. 